\title{
Fatores pré-colheita que afetam a qualidade tecnológica de trigo
}

\author{
Pre-harvest factors that affect wheat technological quality
}

\author{
Lucia de Franceschi ${ }^{\mathrm{I}, \mathrm{I}}$ Giovani Benin ${ }^{\mathrm{I}}$ Eliana Guarienti ${ }^{\mathrm{II}}$ Volmir Sérgio Marchioro ${ }^{\mathrm{III}}$ \\ Thomas Newton Martin ${ }^{\mathrm{I}}$
}

\section{- REVISÃo BIBLIOGRÁFICA -}

\section{RESUMO}

A aptidão tecnológica representa uma oportunidade de agregar valor de mercado ao trigo, principalmente em face do mercado internacional e do setor industrial, o qual busca diferencial de qualidade aos seus produtos. Os fatores genéticos, meteorológicos e de manejo são determinantes para a obtenção da qualidade desejada. Nesse sentido, a adequada escolha da cultivar, o conhecimento das limitações climáticas da região de cultivo e da fertilidade do solo e a execução dos tratos culturais recomendados pela pesquisa podem contribuir substancialmente para a obtenção das características físicas, químicas e biológicas que conferem qualidade à farinha e aos produtos derivados de farinha, conforme abordado nesta revisão.

Palavras-chave: Triticum aestivum L., proteína, interação genótipo x ambiente, pré-colheita.

\section{ABSTRACT}

Technological performance represents an opportunity to add market value to wheat, especially considering international market and industrial sector which seek to achieve distinctive quality of their products. Genetic, metereological, and management factors are crucial to obtain the desired quality. With respect to the selection of an adequate cultivar, knowledge about the climatic limitations of the wheat-growing region and soil fertility, and accomplishing the management practices recommended by research can substantially contribute toward obtaining the physical, chemical, and biological characteristics that lend quality to flour and flour-based products, as discussed in this review.
Key words: Triticum aestivum L., protein, genotype $\times$ environment interaction, pre-harvest.

\section{INTRODUÇÃO}

O cultivo do trigo é de extrema importância para a sustentabilidade de pequenas e médias propriedades da região Sul do Brasil, estando altamente integrado em esquemas de rotação/sucessão com as culturas da soja e do milho, no sistema de semeadura direta. Em face de um mercado globalizado e da necessidade do Brasil atingir a autosuficiência na produção, busca-se maior competitividade na triticultura nacional. Para tanto, é necessário incrementar o potencial de rendimento em nível de lavoura, no qual as cultivares devem favorecer-se de forma benéfica do ambiente e manejo empregado (SMANHOTTO et al., 2006). Além da produtividade, o grão de trigo também deve possuir a qualidade tecnológica desejada pela indústria, evitando assim o uso de aditivos, por razões de custo e de segurança alimentar.

Os atributos que influem na qualidade tecnológica são determinados, principalmente, pelo teor de proteínas (POMERANZ, 1973) e por sua variação,

'Universidade Tecnológica Federal do Paraná (UTFPR), Campus Pato Branco. Via do Conhecimento, km 01, 85501-970, Pato Branco, PR, Brasil. E-mail: luciafranceschi@yahoo.com.br. Autor para correspondência.

IEMBRAPA-Centro Nacional de Pesquisa de Trigo (CNPT), Passo Fundo, RS, Brasil.

II'Cooperativa Central de Pesquisa Agrícola, Tecnologia da Nossa Terra (COODETEC), Cascavel, PR, Brasil. 
tanto qualitativa, em termos da composição de subunidades, quanto quantitativa, em relação às diferentes frações protéicas que compõem o glúten (BRUNORI et al., 1989), sendo as gluteninas e as gliadinas as principais responsáveis pelas propriedades reológicas da massa (POMERANZ, 1988). A variação qualitativa e a variação quantitativa dessas proteínas dependem do genótipo (G), do ambiente (A) e da interação GxA (GUARIENTI, 1996).

As variações de qualidade devido ao ambiente superam com freqüência as vinculadas ao genótipo (PETERSON et al., 1998). Dentre os fatores ambientais que podem produzir modificações na qualidade tecnológica e no teor protéico do grão, citam-se o tipo de solo e os níveis de adubação (MAC RITCHIE \& GUPTA, 1993). Dentre os fatores meteorológicos, a temperatura, a precipitação pluvial e a radiação solar são os de maior impacto, tanto no crescimento, quanto no desenvolvimento, na adaptação e na qualidade tecnológica do trigo (MIRALLES \& SLAFER, 2000). Nesse sentido, a forma mais eficiente que o produtor dispõe para reduzir riscos é o emprego de práticas de manejo das culturas, tais como escolha de cultivar, época e densidade de semeadura, manejos de água, resíduos na superfície e fertilização, as quais buscam minimizar o impacto das flutuações climáticas.

Dessa forma, o objetivo desta revisão bibliográfica é fornecer informações que possam auxiliar o grau de entendimento dos fatores pré-colheita que afetam a qualidade tecnológica de trigo a fim de que a adoção de técnicas que otimizem, tanto a qualidade tecnológica, quanto a produtividade, seja empregada de forma mais adequada.

\section{1) Fatores genéticos}

O genoma D (proveniente da espécie Aegilops squarrosa L.), possivelmente o responsável pela qualidade tecnológica do trigo, foi incorporado aos trigos tetraploides (AABB) por meio de hibridações naturais e, quando seguido de poliploidia, produz o trigo hexaplóide (AABBDD), como é o caso de Triticum aestivum $\mathrm{L}(2 \mathrm{n}=6 \mathrm{x}=42)$ (SILVA et al., 2004).

As proteínas do glúten, presentes no endosperma da semente, representam $85 \%$ das proteínas da farinha e são as principais responsáveis pela qualidade panificativa do trigo (BRAMMER, 2000). Essas proteínas são classificadas em dois grupos: as gluteninas (alto e baixo peso molecular), responsáveis pela elasticidade, e as gliadinas, responsáveis pelas características de viscosidade. Segundo CALDEIRA et al. (2000), cada proteína é produto de, pelo menos, um gene, sem haver modificações pós-traducionais, excetuando-se a formação de pontes de dissulfeto.
Dessa forma, a qualidade tecnológica de trigo é determinada, principalmente, pela fração das proteínas do glúten do grão, a qual é extremamente influenciada pelos alelos dos locos que as codificam, o que demonstra a grande importância prática da identificação desses alelos (BRAMMER, 2000). As gluteninas de alto peso molecular (HMW-GS) são do tipo poliméricas e são estabilizadas pelas pontes dissulfeto, resultantes da ligação dos resíduos de cisteína. As subunidades de HMW-GS são codificadas por genes Glu-1 localizados no braço longo do primeiro grupo homólogo da espécie (cromossomos 1A, 1B e $1 D$ ), que podem codificar para um ou dois tipos de polipeptídeos. Numerosos alelos, responsáveis pela produção de subunidades diversas, têm sido descritos para cada loco. Glu-1B apresenta maior polimorfismo, com cinco alelos comuns e, pelo menos, seis alelos raros. Glu-1D apresenta dois alelos comuns e quatro alelos raros, e Glu-1A é o loco menos polimórfico, com apenas três alelos, em que um é nulo e nos outros dois um tipo de polipeptídeo não é funcional. Essa variação na composição das subunidades de gluteninas (composição alélica) contribui para as diferenças genéticas na qualidade de panificação observada entre genótipos, seja por produzirem maior quantidade de HMW-GS, seja por produzirem subunidades mais efetivas (PAYNE et al., 1984; CALDEIRA et al., 2000). De acordo com BRAMMER (2000), os padrões eletroforéticos obtidos com essas proteínas podem relacionar 69\% da variação da qualidade de panificação em um genótipo de trigo.

A qualidade tecnológica também pode ser estimada por meio das gluteninas de baixo peso molecular (LMW-GS), que estão mapeadas no loco Glu-3 do braço curto dos cromossomos 1A, 1B e 1D e próximas ao loco Gli-1 que codifica as gliadinas (SINGH \& SHEPHERD, 1988). Já as gliadinas são proteínas monoméricas responsáveis pela extensibilidade da massa para produção de pão, possuem baixo peso molecular, têm composições características do genótipo e são independentes das condições de crescimento da planta, sendo sua análise atrativa para identificação varietal(WRIGLEY, 1976).

Contudo, é válido ressaltar que o conteúdo de proteína é um caráter quantitativo, expresso por grande número de genes, os quais são decisivamente influenciados pelo ambiente. Entretanto, em três cruzamentos envolvendo cultivares de trigo duro com força de glúten contrastantes, CLARKE et al. (1993) obtiveram valores de herdabilidade moderados $(0,57$, 0,67 e 0,68) quanto aos valores do índice de sedimentação. Já MITTELMANN et al. (2000), analisando a herança dos caracteres do trigo 
relacionados à qualidade de panificação (volume de sedimentação, índice de sedimentação e teor de proteína) em 10 cruzamentos envolvendo cinco cultivares (classificadas distintamente quanto à qualidade de panificação), detectaram variabilidade nos cruzamentos, no tocante aos caracteres avaliados, sugerindo a existência de genes complementares. Além disso, esses autores encontraram valores de herdabilidade para volume de sedimentação variando entre 0,04 e 0,76 (média de 0,44) e observaram que esse caráter está fortemente associado com o índice de sedimentação, como era esperado, uma vez que esse índice é obtido pela divisão do volume de sedimentação pelo teor de proteína.

\section{2) Elementos meteorológicos}

O clima tem profundo impacto na produção de trigo e ajuda a explicar porque diferentes partes do mundo produzem distintos tipos de trigo, condicionando, por sua vez, o seu destino final de uso (BOZZINI, 1988). Na região temperada do Brasil (Rio Grande do Sul, Santa Catarina e Sul do Paraná), os principais problemas são o excesso de umidade relativa do ar em setembro-outubro, as temperaturas elevadas na fase de enchimento de grãos, as chuvas na colheita, o granizo e a ocorrência de geadas no espigamento (NODA et al., 1994).

A duração das distintas fases ontogênicas do cultivo do trigo é regulada por três fatores determinantes: i) temperatura; ii) fotoperíodo (duração do dia); iii) vernalização (requerimentos de horas de frio). Entretanto, a temperatura e a precipitação pluvial são os fatores que mais diretamente relacionados à qualidade tecnológica.

a) Temperatura: a temperatura, em particular, induz uma série de mudanças fisiológicas na acumulação de reservas no grão, que interagem de maneira complexa, modificando a qualidade tecnológica. A temperatura ótima do período da antese até a maturação fisiológica para a obtenção de elevado peso de grãos deve ser em torno de $16^{\circ} \mathrm{C}$ (KOLDERUP, 1975). A partir desta ocorre diminuição do rendimento de grão na ordem de 3 a $4 \%$ a cada grau centígrado de aumento (WARDLAW \& WRIGLEY, 1994). Esse fenômeno ocorre, principalmente, devido à redução na deposição de amido. A acumulação de proteína também declina quando a temperatura aumenta, embora seja menos sensível que o amido (RANDALL \& MOSS, 1990).

Nas cultivares cujo destino principal é a panificação e a elaboração de macarrão, o aumento na porcentagem de proteína conduz a melhoria na força da massa (MATSUO et al., 1972). No entanto, quando a temperatura durante o enchimento de grão supera os $30^{\circ} \mathrm{C}$, a relação positiva entre porcentagem de proteína e força da massa deixa de existir, podendo inclusive se tornar negativa (CIAFFI et al., 1996). Em alguns casos, mesmo sem a modificação do conteúdo protéico do grão, o estresse térmico conduz a diminuição no volume do pão e no volume de sedimentação (PETERSON et al., 1998).

Quando ocorre estresse térmico, a síntese de gliadinas e as subunidades de gluteninas de baixo peso molecular não são afetadas. Entretanto, as subunidades de gluteninas de alto peso molecular são reduzidas, podendo ser paralisadas (BLUMENTHAL et al., 1994). O tamanho relativo das proteínas poliméricas depende de sua composição, em particular da relação entre subunidades de gluteninas de alto e baixo peso molecular. Assim, a redução ou supressão da síntese de gluteninas de alto peso afeta negativamente a formação de agregados responsáveis pela coesividade do glúten e da firmeza das massas (SHEWRY et al., 2003).

Experiências realizadas com trigo para pão e trigo para massas, na Itália, demonstraram que a ocorrência de temperaturas muito altas $\left(35-40^{\circ} \mathrm{C}\right)$ durante o enchimento de grãos afeta substancialmente a acumulação de matéria seca e de proteína (CORBELLINI et al., 1997). Da mesma forma, na região das grandes planícies dos Estados Unidos, em estudo de avaliação da evolução de 30 cultivares de trigo duro de inverno em 17 ambientes, PETERSON et al. (1998) registraram diminuições significativas nos volumes de sedimentação (SDS) e nas porcentagens de absorção de água e volume de pão, devido ao efeito do estresse térmico (número de horas com temperatura superior a $\left.32^{\circ} \mathrm{C}\right)$.

A avaliação da influência das temperaturas mínima e máxima na qualidade tecnológica e no rendimento de grãos da cultivar de trigo 'EMBRAPA 16', nos anos de 1990 a 1998, em sete locais do Rio Grande do Sul e em quatro locais de Santa Catarina, conforme observado por GUARIENTI et al. (2004), determinou que o aumento da temperatura máxima média nesses locais no final do enchimento de grãos promoveu elevação da força de glúten e acréscimo do peso de mil grãos e do rendimento de grãos, além de influenciar positivamente o número de queda. Entretanto, ocasionaram redução do peso do hectolitro, quando ocorreram no início do enchimento de grãos. Já sob temperaturas mínimas médias, esses mesmos autores observaram influência negativa sobre o peso do hectolitro, peso de mil grãos e número de queda e da extração experimental de farinha na fase inicial de enchimento de grãos. Entretanto, essas temperaturas 
tiveram influência positiva na força de glúten e na relação $\mathrm{P} / \mathrm{L}$, nos períodos que correspondem, aproximadamente, ao início e ao fim do enchimento de grãos.

b) Precipitação pluvial: a cultura do trigo, quando comparada a outras culturas, possui maior eficiência no uso da água, em decorrência de ser originária de regiões semiáridas (SCHLEHUBER \& TUCKER, 1967). Entretanto, a fotossíntese, a formação e a remobilização de metabólitos e o estabelecimento do número de grãos viáveis por espiga são afetados durante a ocorrência de deficiência hídrica (GUSTA \& CHEN, 1987). A redução na produção de fotoassimilados pode estimular a remobilização de reservas para os grãos ou reduzir o seu acúmulo, dependendo da época de ocorrência.

A elevada precipitação pluvial antes da maturação fisiológica do trigo promove decréscimo no enchimento do grão, diminuindo o peso de mil grãos e aumentando a atividade enzimática (HIRANO, 1976). Esta última é apontada como a principal causa da redução das características qualitativas da farinha, pois as enzimas ativadas promovem alterações no amido e nas proteínas, sendo comum a germinação do grão ainda na espiga (LINHARES \& NEDEL, 1989; CUNHA, 1999). Além disso, chuvas frequentes intensificam a ocorrência de moléstias (WEIBEL \& PENDLETON, 1964) e o acamamento da planta (CRUZ et al., 2000), fatores relacionados, tanto com a produtividade, quanto com a qualidade tecnológica.

A germinação pré-colheita do trigo é induzida quando os grãos absorvem água logo depois de completada a maturação e, com isso, ocorre a ativação da enzima a-amilase (sintetizada na camada de aleurona do endosperma), que é responsável pela redução da qualidade da farinha (NODA et al., 1994). Assim, o molhamento e a posterior secagem dos grãos também reduzem o peso do hectolitro, em conseqüência da diminuição de sua densidade (FINNEY \& YAMAZAKI, 1967). De acordo com BHATT et al. (1981), a redução do peso do hectolitro é resultante da alta taxa de respiração, associada aos grãos germinados, que consomem os carboidratos acumulados. Chuvas no período inicial da maturação afetam, principalmente, características quantitativas (peso de mil grãos, peso do hectolitro e rendimento de farinha) e incrementam o teor de cinzas, enquanto que chuvas no fim da maturação reduzem a estabilidade, a elasticidade e a extensibilidade da massa, bem como sua viscosidade (HIRANO, 1976).

A precipitação, a umidade relativa do ar e o excesso hídrico do solo influenciam negativamente o peso de hectolitro, o peso de mil grãos, o número de queda, a relação P/L e o rendimento de grãos. A umidade relativa do ar apresenta menor influência sobre o peso do hectolitro no peso de mil grãos e rendimento de grãos, em comparação com o excesso hídrico (GUARIENTI et al., 2003, 2005).

\section{3) Fertilidade do solo}

A qualidade de panificação do trigo é associada, frequentemente, com os níveis de proteína no grão, a quantidade e qualidade do glúten e as propriedades reológicas da massa. O nitrogênio e o enxofre são os nutrientes que com maior freqüência condicionam a obtenção de conteúdos acentuados de glúten e de proteína nos grãos de trigo (FALOTICO et al., 1999).

a) Nitrogênio: conforme relata FINNEY et al. (1957), o aumento do conteúdo de nitrogênio nos grãos de trigo melhora a qualidade de panificação, uma vez que variações do conteúdo protéico da farinha afetam a força do glúten, ou seja, quanto menor o conteúdo de proteína na massa de panificação, menores são sua força e extensibilidade, bem como sua qualidade de panificação. Entretanto, para PORCEDDU (1990), um elevado conteúdo de proteínas não é, por si só, indicativo de boa qualidade, visto que a qualidade de panificação depende da composição e da interação das principais proteínas de glúten (gluteninas e gliadinas), as quais devem apresentar uma combinação ideal entre quantidade e qualidade. Além disso, de acordo com SANGOI et al. (2007), genótipos com bases genéticas diferentes também apresentam resposta diferenciada à aplicação de nitrogênio.

$\mathrm{O}$ trigo necessita acumular 30-33kg de $\mathrm{N}$ na biomassa aérea por tonelada de grão produzido. Se essa taxa de acumulação for inferior a $25 \mathrm{~kg}$ de N/t, o conteúdo de proteína resultante nos grãos colhidos será menor que 10\% (FOWLER, 1998). Os baixos conteúdos de proteína ocorrem normalmente quando existe baixa fertilidade do solo e baixo conteúdo de nitrogênio em etapas posteriores à aparição do primeiro nó na planta. Por essa razão, é necessário aplicar o fertilizante nitrogenado de tal maneira que este permita o desenvolvimento ótimo da planta e um adequado acúmulo de proteína no grão.

Há relação linear entre o incremento no conteúdo protéico do grão e as doses de nitrogênio aplicadas, entretanto, apenas até quando os níveis de rendimento não superarem os $3.500 \mathrm{~kg} \mathrm{ha}^{-1}$ (BERGH et al., 1998). Quando os rendimentos unitários superarem $4.500 \mathrm{~kg} \mathrm{ha}^{-1}$, a relação linear deixa de existir (RIZZALLI et al., 1984). A obtenção de grãos com porcentagens de proteínas superiores a $12,5 \%$ e com níveis de rendimento superiores a $5.000 \mathrm{~kg} \mathrm{ha}^{-1}$ requerem aplicações fracionadas de nitrogênio. 
O conteúdo de proteína no grão e a força de glúten aumentam, tanto com aplicações de nitrogênio na época recomendada, quanto em aplicações tardias, ou seja, em período próximo ao ou durante o espigamento (ECHEVERRÍA \& STUDDERT, 1998). Normalmente,, aplicações mais tardias de N somente aumentam o conteúdo de proteína no grão mas, raramente promovem aumento no rendimento de grãos (SPIERTZ \& DE VOS, 1983). Enquanto que uma maior disponibilidade de $\mathrm{N}$ nas fases iniciais de desenvolvimento das plantas promove um maior acúmulo de biomassa, crescimento foliar, afilhamento e maior percentual de sobrevivência de afilhos o qual tem influência no número de espiguetas férteis por espiga. A importância da realocação de biomassa para os grãos advém do fato de que os aumentos na produtividade de trigo estão normalmente associados com o índice de colheita (LOSS \& SIDDIQUE, 1994).

Há ainda uma estreita relação entre conteúdo de nitrogênio na folha bandeira, durante o estágio de grão leitoso, e porcentagem de proteínas nos grãos no momento da colheita (ECHEVERRÍA \& STUDDERT, 1998). Nesse sentido, BERGH et al. (1999 e 2001) demonstraram que, quando o cultivo de trigo não é exposto a déficit hídrico durante o período de enchimento de grãos, a concentração de nitrogênio na folha bandeira poder ser utilizada como indicador do conteúdo final de proteína nos grãos.

b) Enxofre: o enxofre é um elemento essencial para o desenvolvimento e a manutenção das plantas (NGUYEN \& GOH, 1992). As plantas absorvem esse mineral principalmente na forma de sulfato, o qual está presente no solo em níveis não superiores a $10 \%$ de enxofre, sendo o restante encontrado na forma orgânica (WATKINSON \& KEAR, 1996). A deficiência de enxofre produz a inibição da síntese de proteínas, além de reduzir o rendimento e a qualidade dos cultivos (MENGEL \& KIRKBY, 1987). Nos grãos de trigo, a maior parte desse mineral encontra-se presente nas proteínas, formando aminoácidos sulfurados como metionina, cisteína e cistina, e a sua deficiência resulta em menor concentração destes aminoácidos nos grãos (WRIGLEY et al. 1976; BYERS et al., 1987).

Aumento no rendimento de grãos com a adição de $20 \mathrm{~kg} \mathrm{ha}^{-1}$ de enxofre foi observado por ZHAO et al. (1999), embora respostas positivas no volume de pão somente tenham sido observadas com aplicações a partir de $100 \mathrm{~kg} \mathrm{ha}^{-1}$. CASTLE \& RANDALL (1987), estudando a resposta do enxofre durante o desenvolvimento inicial da semente, observaram menor síntese e acúmulo protéico na deficiência desse mineral, o que provocou redução no período inicial de desenvolvimento da semente, o qual é caracterizado pela alta divisão celular e pela baixa taxa de acumulação de proteínas.

Algumas das variações na magnitude da resposta ao enxofre podem ser atribuídas a diferenças no fornecimento de nitrogênio, isso porque o nitrogênio e o enxofre são componentes estruturais das proteínas. Dessa forma, ambos os elementos estão interrelacionados na formação dessas moléculas orgânicas (LUO et al., 2000). A disponibilidade de enxofre no solo melhora a eficiência do uso de nitrogênio, pois, para cada 14 partes de nitrogênio empregadas na formação de aminoácidos, é necessária uma parte de enxofre (NGUYEN \& GOH, 1992). Portanto, para que se possa ter boa qualidade e rendimentos elevados em trigo, é essencial considerar o balanço entre nitrogênio e enxofre em grãos. Para isso, deve-se considerar a dose, as fontes e os momentos de aplicação.

\section{4) Rotação de culturas}

As características dos grãos e da farinha de trigo, bem como sua aptidão para os diferentes usos industriais, são influenciadas pela rotação de culturas. Nesse sentido, BORGHI et al. (1995) verificaram que o sistema de rotação milho/trigo/alfafa aumentou o teor protéico e os valores alveográficos, comparativamente à rotação de milho/trigo. No entanto, a maior concentração de proteínas foi obtida com a monocultura de trigo. Segundo os autores, isso aconteceu em razão da menor produtividade observada no sistema de monocultura, que possibilita o aumento da concentração de proteínas. GUARIENTI et al. (2000) também observaram que a monocultura de trigo eleva a força geral de glúten e a microssedimentação com lauril sulfato de sódio. Esses mesmos autores observaram que o preparo convencional de solo com arado de discos e o cultivo mínimo reduzem o número de queda em comparação com o plantio direto, e o sistema de rotação com dois invernos sem trigo eleva o peso do hectolitro em comparação com a monocultura. Da mesma forma, LÓPEZ-BELLIDO et al. (1998) observaram que sistemas de rotação de culturas que envolvem uma leguminosa, como o grão-de-bico e a fava, elevam o teor protéico e melhoram as propriedades reológicas da massa.

\section{CONCLUSÕES}

Os avanços tecnológicos obtidos nas últimas décadas pelo melhoramento genético de trigo no Brasil possibilitaram o desenvolvimento de cultivares com diferentes qualidades tecnológicas. Tais cultivares precisam ser aproveitadas de forma a maximizar a produtividade e a qualidade nas diferentes 
regiões de cultivo, em resposta aos fatores meteorológicos e de manejo.

A escolha do genótipo, a ocorrência de temperaturas máximas, médias e mínimas, a distribuição da precipitação pluvial, a adubação e o estabelecimento de esquemas de rotação de culturas com leguminosas estão entre os principais fatores que devem ser observados para a obtenção da qualidade tecnológica desejada.

\section{REFERÊNCIAS}

BERGH, R. et al. Nutrición nitrogenada y proteína en trigo candeal. In: CONGRESO NACIONAL DE TRIGO, 5., 2001, Villa Carlos Paz, Córdoba. Actas: V Congresso 3er Simpósio Nacional de Cereales. Villa Carlos Paz, Córdoba, 2001.

BERGH, R. et al. Diagnóstico de la fertilización nitrogenada para calidad em trigo. In: Seminário diagnósticos de deficiências de $N$, $P$ y $S$ em cultivos de la region pampeana. INTA, IPG, SAGPyA (Secretaría de Agricultura, Ganadería, Pesca y Alimentos) Buenos Aires, 1999. p.21-30.

BERGH, R. et al. Fertilización nitrogenada del trigo Candeal em el centro sur bonaerense: aplicaciones tardías. Actas: IV Congresso nacional de trigo - II simposio nacional de cereales de siembra otono - invernal, Mar del Plata, 1998.

BHATT, G.M. et al. Pre harvest sprouting in hard winter wheat's: assessment of methods to detect genotypic and nitrogen effects and interactions. Cereal Chemistry, St. Paul, v.58, n.4, p.300-302, 1981.

BYERS, M. et al. The nitrogen and sulfur nutrition of wheat and its effect on the composition and baking quality of the grain. Aspects Applied Biology, v.15, p.337-344, 1987.

BLUMENTHAL, C. et al. The heat shock response relevant to molecular and structural changes in wheat yield and quality. Australian Journal of Plant Physiology, Camberra, v.21, p.901-909, 1994

BRAMMER, S.P. Marcadores moleculares: princípios básicos e uso em programas de melhoramento genético vegetal. Passo Fundo: Embrapa Trigo, 2000.

BRUNORI, A. et al. Bread-making quality indices in Triticum aestivum progenies: implications in breeding for better bread wheat. Plant Breeding, Berlin, v.102, p.222-231, 1989.

BORGHI, B. et al. Influence of crop rotation, manure and fertilizers on bread making quality of wheat (Triticum aestivum L.). European Journal of Agronomy, Amsterdam, v.4, n.1, p.37-45, 1995.

BOZZINI, A. Origin, distribution, and production of durum wheat in the world. In: FABRIANE, G.; LINTAS, C. Durum wheat: chemistry and technology. St. Paul, Minnesota: Am Assoc Cereal Chem, 1988. Cap.1, p.332.

CALDEIRA, M.T.M; et al. TRIGO - Diversidade de trigos, tipificação de farinhas e genotipagem. Biotecnologia Ciência \& Desenvolvimento, v.16, p.44-48, 2000.
CASTLE, S.L.; RANDALL, P.J. Effects of sulfur deficiency on the synthesis and accumulation of proteins in the developing wheat seed. Australian Journal of Plant Physiology, Camberra, v.14, p. 503-516, 1987.

CIAFFI, M. et al. Effect of heat shock during grain filling on the gluten composition of bread wheat. Journal of Cereal Science, Reino Unido, v.24, n.2, p.91-100, 1996.

CLARKE, J.M. et al. Selection for gluten strength in three durum wheat crosses. Crop Science, Madison, v.33, n.5, p.956958, 1993

CORBELLINI, M. et al. Effect of the duration and intensity of heat shock during grain filling on dry matter and protein accumulation, technological quality and protein composition in bread and durum wheat. Australian Journal of Plant Physiology, Camberra, v.24, p.245-260, 1997.

CRUZ, P.J. et al. Efeito do acamamento induzido em trigo. Revista Brasileira de Agrociência, v.6, n.2, p.112-114, 2000 .

CUNHA, G.R. El Nino oscilação do Sul e perspectivas climáticas aplicadas no manejo de culturas no sul do Brasil. Revista Brasileira de Agrometeorologia, Santa Maria, v.7, n.2, p.277-284, 1999.

ECHEVERRÍA, H.E.; STUDDERT, G.A. El contenido de nitrogeno en la hoja bandera del trigo como predictivo del incremento de proteina en el grano por aplicaciones de nitrógeno en la espigón. Revista de la facultad de Agronomia, La Plata v.103, n.1, p.27-36,1998.

FALOTICO, J. et al. Nutrición nitrogenada del trigo bajo siembra directa y labranza convencional. Ciencia del Suelo. Buenos Aires - Argentina, v.17, p.9-20, 1999.

FINNEY, K.F. et al. Effects of foliar spryng on Pawnee wheat with urea solutions on yield protein content, and protein quality. Agronomy Journal. v.49, p.341-347, 1957.

FINNEY, K.; YAMAZAKI, W. Quality of hard, soft and durum wheat's. In: QUNSENBERRY, K.S.; REITZ, L.P. (Ed.). Wheat and wheat improvement. Madison: American Society of Agronomy, 1967. p.471-50. 3 (ASA Agronomy, 13).

FOWLER, D.B. The importance of crop management and cultivar genetic potencial in the production of wheat with hight protein concentration. En: Wheat protein production and marketing. University Extension Press, U of Saskatchewan. Canadá. 1998. p.285-290.

GUARIENTI, E.M. Qualidade industrial de trigo. Passo Fundo: EMBRAPA - CNPT, 1996. 36p. (EMBRAPA - CNPT. Documentos, 27).

GUARIENTI, E.M. et al. Influência do manejo do solo e da rotação de culturas na qualidade industrial do trigo. Pesquisa Agropecuária Brasileira, Brasília, v.35, n.12, p. 2375-2382, 2000. Disponível em: <www.scielo.br/pdf/pab/v35n12/ a07v3512.pdf>. Doi: 10.1590/S0100-204X2000001200007.

GUARIENTI, E. M. et al. Avaliação do efeito de variáveis meteorológicas na qualidade industrial e no rendimento de grãos 
de trigo pelo emprego de análise de componentes principais. Ciência e Tecnologia de Alimentos, Campinas, v.23, n.3, p.500-510, 2003. Disponível em: <www.scielo.br/pdf/cta/v23n3/ 18861.pdf $>$. Doi: 10.1590/S0101-20612003000300034.

GUARIENTI, E.M. et al. Influência das temperaturas mínima e máxima em características de qualidade industrial e em rendimento de grãos de trigo. Ciência e Tecnologia de Alimentos, Campinas, v.24, n.4, p.505-515, 2004. Disponível em: <www.scielo.br/pdf/cta/v24n4/a05v24n4.pdf>. Doi: 10.1590/S0101-20612004000400005.

GUARIENTI, E.M. et al. Efeitos da precipitação pluvial, da umidade relativa do ar e de excesso e déficit hídrico do solo no peso do hectolitro, no peso de mil grãos e no rendimento de grãos de trigo. Ciência e Tecnologia de Alimentos, Campinas, v.25, n.3, p.412-418, 2005. Disponível em: <http:/ / w w w.scielo.br/scielo.php? pid=s 0101 20612005000300004\&script=sci_arttext $>$. Doi: 10.1590/ S0101-20612005000300004.

GUSTA, L.V., CHEN, T.N.H. The physiology of water and temperature stress. In: HEYNE, E.G. (Ed.). Wheat and wheat improvement. Madison, Wisconsin: ASA, 1987. p.115-150.

HIRANO, J. Effects of rain in ripening period on the grain quality of wheat. Japan Agricultural Research Quarterly, Ibaraki, v.10, n.4, p.168-173, 1976.

KOLDERUP, F. Effects of temperature, photoperiod and light quality on protein production in wheat grains. Journal of the Science of Food and Agriculture, Noruega, v.26, p.583592, 1975.

LINHARES, A.G., NEDEL, J.L. Clima e germinação do grão do trigo na espiga. In: MOTA, F.S. (Ed.). Agrometeorologia do trigo no Brasil. Campinas: Sociedade Brasileira de Agrometeorologia, 1989. p.95-97.

LÓPEZ-BELLIDO, L. et al. Effects of tillage, crop rotation and nitrogen fertilization on wheat-grain quality grown under rainfed Mediterranean conditions. Field Crops Research, Amsterdam, v.57, n.3, p.265-276, 1998.

LOSS, S.P.; SIDDIQUE, K.H.M. Morphological and physiological traits associated with wheat yield increases in Mediterranean environments. Advances in Agronomy, University of Delaware, Newark, USA, v.52, p.229-276, 1994.

LUO, C. et al. The effect of nitrogen and sulfur fertilization and their interaction with genotype on wheat glutenins and quality parameters. Journal of Cereal Science, Reino Unido, v.31, p.185-194, 2000.

MAC RITCHIE, F.; GUPTA, R.B. Functionality composition relationships of wheat flour as a result of variation in sulphur availability. Australian Journal of Agricultural Research, Victoria, v.44, n.8, p.1767-1774, 1993.

MATSUO, R. et al. Effect of protein content on cooking quality of spaghetti. Cereal Chemistry, Saint. Paul, v.49, n.6, p.707-711, 1972.

MENGEL, K.; KIRKBY, E. Sulphur. In: INTERNATIONAL POTASH INSTITUTE (Ed.). Principles of plant nutrition. Bern, Switzerland, 1987. p.385-402.
MIRALLES, D.J.; SLAFER, G.A. Wheat development. In: SATORRE, E.H.; SLAFER, G.A. (Eds.). Wheat: ecology and physiology of yield determination. New York: Food Products, 2000. p.13-43

MitTELmANN, A. et al. Herança de caracteres do trigo relacionados à qualidade de panificação. Pesquisa Agropecuária Brasileira, Brasília, v.35, n.5, p.975-983, 2000. Disponível em: $<$ http://www.scielo.br/scielo.php?pid=S 0100 204X2000000500015\&script $=$ sci_abstract $\&$ tlng $=$ pt $>$. Doi: 10.1590/S0100-204X2000000500015.

NGUYEN, M.L.; GOH, K.M. Nutrient cycling and losses based on a mass-balance model in grazed pastures receiving longterm superphosphate applications in New Zealand. 2. Sulphur. Journal of Agricultural Science, Cambridge, v.119, p.107122, 1992.

NODA, K. et al. Response of wheat grain to ABA and imbibition at low temperature. Plant Breeding, Berlin, v.113, n.1, p.5357, 1994.

PAYNE, P.I. et al. Genetic linkage between endosperm protein genes on each of the short arms of chromosomes $1 \mathrm{~A}$ and $1 \mathrm{~B}$ in wheat. Theoretical and Applied Genetics, Berlin, v.67, p.235-243, $1984 . \quad$ Disponível em: <http:// www.springerlink.com/content/ v50q35rp83740526/>. Doi: 10.1007/BF00317044.

PETERSON, C.J., et. al. Baking quality of hard winter wheat: response of cultivars to environments in the Great Plains. Euphytica, v.100, p.157-162, 1998.

POMERANZ, Y. From wheat to bread: a biochemical study. American Scientist, New Haven, v.61, n.6, p.683-691, 1973.

POMERANZ, Y. Composition and functionality of wheat flour components. In: Wheat: chemistry and technology. Volume I edited by Y. Pomeranz. St. Paul: American Association of Cereal Chemists, 1988. V.2, cap.5, p.219-370.

PORCEDDU, E. Aspetti genetici e biochimici delle proteine dei frumenti e qulità tecnologiche dei frumenti duri. Itália, (S.I.:s.n) p.75-88, 1990.

RANDALL, P.J.; MOSS, H.J. Some effects of temperature regime during grain filling on wheat quality. Australian Journal of Agricultural Research, Victoria, v.41, n.4, p.603$617,1990$.

RIZZALLI, R.H. et al. Efecto del manejo y estación del año sobre la capacidad de mineralización y biomasa total en un Argiudol típico del sudeste bonaerense. Ciencia del Suelo, Buenos Aires, v.2, p.61-67, 1984.

SANGOI, L. et al. Características agronômicas de cultivares de trigo em resposta à época da adubação nitrogenada de cobertura. Ciência Rural, Santa Maria, v.37, n.6, p.1564-1570, 2007. Disponível em: <http://www.scielo.br/scielo.php?pid=S0103$84782007000600010 \&$ script $=$ sci_arttext $\&$ tlng $=$ ene $>$. Doi: 10.1590/S0103-84782007000600010.

SCHLEHUBER, A.M.; TUCKER, B.B. Culture of wheat. In: QUISENBERRY, K.S.; REITS, L.P. (Ed.). Wheat and wheat improvement. Madison: American Society of Agronomy, 1967. p.154-160.

Ciência Rural, v.39, n.5, ago, 2009. 
SHEWRY, P.R. et al. The high molecular weight subunits of wheat glutenin and their role in determining wheat processing properties. Advances in Food and Nutrition Research, San Diego, v.45, p.219-302, 2003.

SILVA, S.A. et al. Composição de subunidades de gluteninas de alto peso molecular (HMW) em trigos portadores do caráter “stay-green”. Ciência Rural, Santa Maria, v.34, n.3, p.679683, 2004. Disponível em: <http://www.scielo.br/

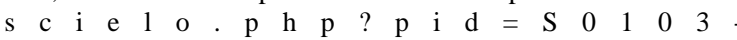
$84782004000300005 \&$ script $=$ sci_arttext $\&$ tlng $=p t>$. Doi: 10.1590/S0103-84782004000300005

SINGH, N.K.; SHEPHERD, K.W. Linkage mapping of the genes controlling endosperm protein in wheat. I. Genes on the short arms of group 1 chromosome. Theoretical and Applied Genetics, Berlin, v.75, p.628-641, 1988. Disponível em: <http://www.springerlink.com/content/p214164835744188/>. Doi: 10.1007/BF00289132

SMANHOTTO, A. et al. Características físicas e fisiológicas na qualidade industrial de cultivares e linhagens de trigo e triticale. Revista Brasileira Engenharia Agrícola Ambiental, Campina Grande, v.10, n.4, p.867-872, 2006. Disponível em: $<$ ht tp://www.scielo.br/scielo.php?pid=S 1415 43662006000400013\&script=sci_arttext\&tl ng=es $>$. Doi:10.1590/S1415-43662006000400013.
SPIERTZ, J.H.J.; DE VOS, N.M. Agronomical and physiological aspects of the role of nitrogen in yield formation in cereals. Plant and Soil, Dordrecht, v.75, p.379-391, 1983.

WARDLAW, I.F.; WRIGLEY, C.W. Heat tolerance in temperate cereals: an overview. Australian Journal of Plant Physiology, v.21, p.695-703, 1994. Disponível em: <http:// www.springerlink.com/content/p2 7974465k106446/>. Doi:10.1016/j.envexpbot.2007.05.011

WATKINSON, J.H.; KEAR, M.J. Sulfate and mineralizable organic sulphur in pastoral soils of New Zealand. I. A quasi equilibrium between sulphate and mineralizable organic sulphur. Australian Journal of Soil Research, Melbourne, v.34, p.385-403, 1996.

WEIBEL, R.D.; PENDLETON, J.W. Effect of artificial lodging on winter grain yield and quality. Agronomy Journal, Madison, v.56, p.487-488, 1964.

WRIGLEY, C.M. Single-seed identification of wheat varieties use of grain hardness testing, electrophoretic analysis and a rapid test paper for phenol reaction. Journal of the Science of Food and Agriculture, Noruega, v.27, p.429-432, 1976.

ZHAO, F.J. et al. Sulfur assimilation and effects on yield and quality of wheat. Journal of Cereal Science, Reino Unido, v.1, n.17, p.1-15, 1999. 